\author{
Jurnal Mekanova \\ Vol 5. No. 2, Oktober 2019 \\ ISSN : 2502-0498
}

\title{
Rancang Bangun Alat Pengolah Limbah Plastik Berbahan Bakar Biomassa
}

\author{
Pribadyo $^{1}$, Teguh Firmanto ${ }^{2}$ \\ ${ }^{1}$ Jurusan Mesin, Fakultas Teknik, Universitas Teuku Umar, Meulaboh \\ ${ }^{2}$ Mahasiswa Teknik Mesin, Fakultas Teknik, Universitas Teuku Umar, Meulaboh \\ Email: dyo_1806@yahoo.co.id
}

\begin{abstract}
Plastic is a material that is widely used in daily life, because it has advantages such as strong, lightweight and stable. But the plastic on the market today are synthetic polymers made from petroleum are difficult to decompose in nature. Judging from the nature of the plastic constituent is composed of components of petroleum hydrocarbons, the plastic waste has the potential to be converted into fuel. The technique used to restore the plastic material is by breaking the carbon chains or polymers that become hydrocarbons. The purpose of the design tool processing waste plastics into fuel oilfired biomass is to design a waste treatment plant in the plastic to produce oil (fuel), making the design drawings of the equipment is planned, determine the materials to be used, make and assemble the apparatus according to the design the planned. In pyrolysis occurs tool decomposition process of organic compounds on the materials. This decomposition caused by the heating process without dealing directly with the air with little oxygen. Waste processing equipment plastic that will be planned to include the design of the combustion chamber, reactor design, pipeline design fence steam, design connecting pipe between the reactor and the pipe fence steam. Extensive volume of reactor tubes obtained then has acquired equipment capacity $4 \mathrm{~kg} /$ production.
\end{abstract}

Keywords: plastic waste, biomass, pyrolysis, design, oil

\section{PENDAHULUAN}

Krisis energi yang melanda dunia akhir-akhir ini juga berdampak terhadap Indonesia yang salah satunya adalah diakibatkan akan kebutuhan manusia untuk menggunakan bahan bakar minyak yang semakin meningkat, sedangkan persediaan minyak atau gas bumi sangat terbatas. Seiring dengan perkembangan kemajuan teknologi yang pesat seperti saat ini menuntut orang untuk berperan aktif, berinovasi guna menghasilkan suatu produk yang berkualitas. Oleh karenanya, banyak pihak berlomba-lomba untuk menciptakan atau mengembangkan teknologi dari alat-alat yang memiliki manfaat namun lebih ekonomis salah satunya adalah alat daur ulang sampah plastik.

Plastik merupakan salah satu bahan yang banyak dipakai dalam kehidupan sehari-hari, karena mempunyai keunggulan-keunggulan seperti kuat, ringan dan stabil. Namun plastik yang beredar di pasaran saat ini merupakan polimer sintetik yang terbuat dari minyak bumi yang sulit terurai di alam. Akibatnya semakin banyak yang menggunakan plastik, akan semakin meningkat pula pencemaran lingkungan seperti pencemaran tanah sehingga perlu dicari solusi untuk penanganannya.

Melihat dari sifat penyusun plastik yang tersusun dari komponen hidrokarbon minyak bumi, maka limbah plastik sangat berpotensi untuk dikonversi menjadi bahan bakar minyak. Teknik yang digunakan untuk mengembalikan material plastik tersebut adalah dengan cara pemecahan rantai karbon atau polimer sehingga menjadi hidrokarbon, (Mahendra Fajri Nugraha, et al, 2013). Pada penelitian ini untuk dekomposisi tersebut 


\section{Jurnal Mekanova \\ Vol 5. No. 2, Oktober 2019 \\ ISSN : 2502-0498}

digunakan teknik pirolisis. Untuk maksud tersebut penelitian ini akan merancang bangun alat daur ulang sampah plastik menjadi bahan bakar yang dapat dimanfaatkan dengan bahan bakar biomassa.

\section{METODE PENELITIAN}

Penelitian ini dimulai dari pengumpulan data literatur, perencanaan alat, pembuatan desain gambar, persiapan bahan baku, pembuatan alat, perakitan sampai dengan penyusunan laporan. Penelitian ini dilakukan di Laboratorium Fakultas Teknik Universitas Teuku Umar Meulaboh.

Dalam menyelesaikan masalah yang diangkat, diperlukan data-data dalam rangka penyusunan tugas akhir ini. Pengumpulan data-data tersebut diperoleh melalui studi literatur dan studi lapangan. Data yang dihimpun baik pada studi literatur maupun studi lapangan hanya terbatas pada hal-hal yang berhubungan dengan perencanaan alat pengolah limbah plastik yang terdapat di sekitar kawasan kota Meulaboh dan Nagan Raya.

Mula-mula data yang dikumpulkan di susun dan kemudian dianalisa. Analisa data dilakukan secara teoritis dan dihitung secara matematis yang dilakukan untuk menentukan komponen-komponen yang akan digunakan dengan menghitung parameter-perameter dimensi dari komponen tersebut.

\section{Perencanaan Alat}

Alat pengolah limbah plastik yang akan direncanakan meliputi:

1. Desain ruang bakar

2. Desain reaktor

3. Desain pipa penadah uap

4. Desain pipa penghubung antara reaktor dan pipa penadah uap.

Adapun skema dari desain perencanaan alat ditunjukkan dalam gambar 1. Berikut.

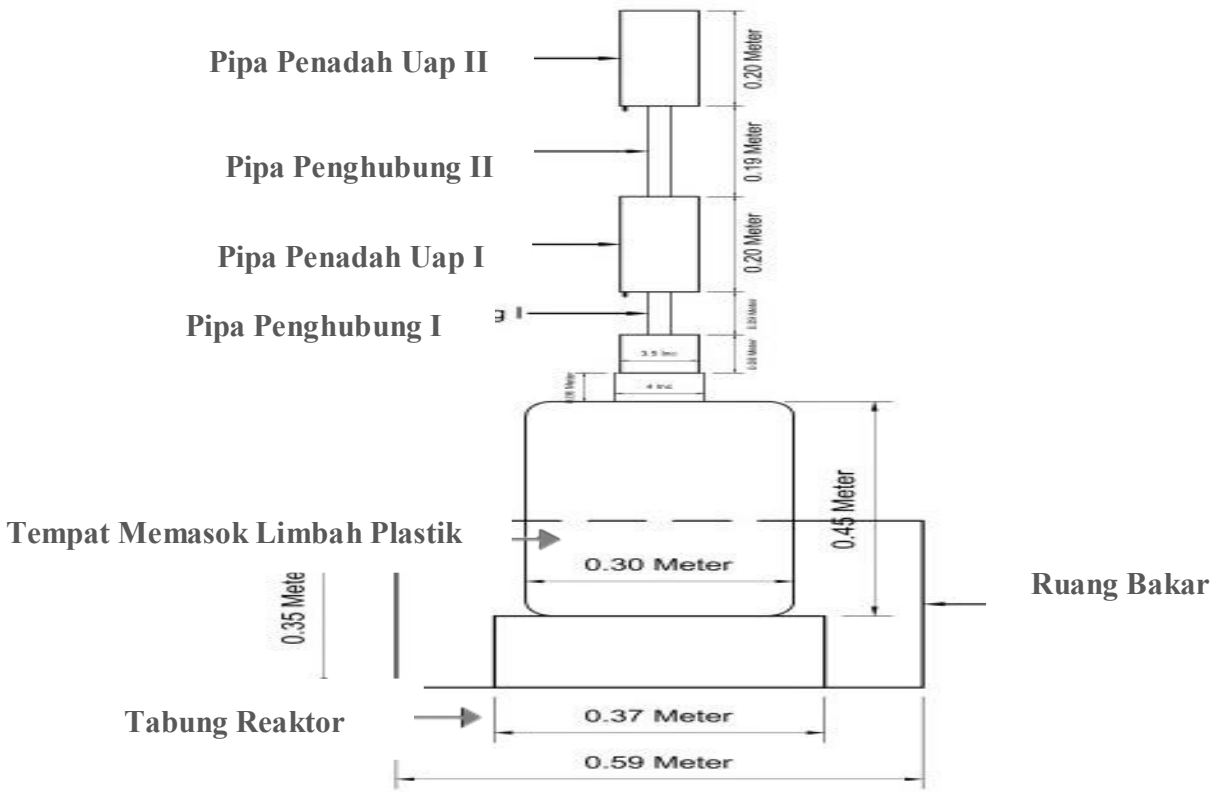

Gambar 1. Skema Desain Alat

Dalam pembuatan dan perakitan alat pengolah limbah plastik ini, beberapa alat dan bahan yang akan digunakan adalah sebagai berikut:

\section{- Alat}

Peralatan yang digunakan dalam penelitian ini ditunjukkan dalam Tabel 3.1 berikut ini: 
Vol 5. No. 2, Oktober 2019

ISSN : 2502-0498

Tabel 1 Alat yang digunakan

\begin{tabular}{|c|l|c|c|}
\hline No & \multicolumn{1}{|c|}{ Nama } & Spesifikasi & Jumlah \\
\hline $\mathbf{1}$ & Mesin Las Listrik & $\begin{array}{l}\text { Prado (DC Inverter MMA } \\
\text { Welder) }\end{array}$ & 1 \\
\hline $\mathbf{2}$ & Elektroda & E6013 RB-26 & 1 kotak \\
\hline $\mathbf{3}$ & Mesin Gerinda & Prohex 3150-002 & 1 \\
\hline $\mathbf{4}$ & Bor Listrik & Prohex & 1 \\
\hline $\mathbf{5}$ & Palu & - & 1 \\
\hline $\mathbf{6}$ & Penggaris & & 1 \\
\hline $\mathbf{7}$ & Pahat besi & & 1 \\
\hline $\mathbf{8}$ & Alat K3 & & 1 \\
\hline $\mathbf{9}$ & Tang & & 2 \\
\hline
\end{tabular}

Spesifikasi alat sebagai berikut:

1. Mesin las busur listrik

Merk

Tipe

Voltase input

Range Arus
: Prado (DC Inverter MMA Welder)

: MPH 120

: 220 Volt

: $10-120 \mathrm{~A}$

2. Mesin gerinda tangan

Merk

: Prohex

Tipe

: 3150-002

Voltase input

: 220 volt

Daya/ arus

: 540 watt / 2.6 Ampere

Ferkuensi

: $50-60 \mathrm{~Hz}$

Putaran

: $11.000 \mathrm{rpm}$

Diameter maks.

- Mata gerinda asah

: 100x6x16 mm

- Mata gerinda potong

: 100x2x16 mm

3. Bor listrik

Merk

: PROHEX

Daya

: 350 watt

Frekuensi

: $50 \mathrm{~Hz}$

Putaran

: $2500 \mathrm{rpm}$

Kapasitas bor

: $\Phi 10 \mathrm{~mm}$

\section{- Bahan}

Bahan yang akan digunakan dalam pembuatan dan perakitan alat pengolah limbah plastik adalah bahan yang mudah diperoleh di Kota Meulaboh dan Nagan Raya. Adapun bahanbahan tersebut adalah sebagai berikut:

- Plat baja tebal $3 \mathrm{~mm}$

- Pipa medium hitam ukuran 3/4 inchi dan 3 inchi

- Pipa sambungan galvanis ukuran 5 inchi

- Plat baja tebal $0,5 \mathrm{~mm}$

Spesifikasi material yang digunakan dapat dilihat pada tabel 2 berikut ini: 


\section{Jurnal Mekanova \\ Vol 5. No. 2, Oktober 2019 \\ ISSN : 2502-0498}

Tabel 2 Spesifikasi Material

\begin{tabular}{|l|l|l|}
\hline \multicolumn{1}{|c|}{ Jenis Material } & \multicolumn{1}{|c|}{ Standart } & \multicolumn{1}{c|}{ Sumber } \\
\hline $\begin{array}{l}\text { Plat baja tebal 3 } \\
\text { mm }\end{array}$ & JIS G & $\underline{\text { http://bsn.go.id/main/berita/berita det/21 }}$ \\
& $\begin{array}{l}\text { 26 (SG, kelas SG } \\
\text { 255), SG 30 } \\
\text { (SG 295). }\end{array}$ & $\underline{\text { 60\#.VNWT-11b-o8 }}$ \\
& SCH-40 & $\begin{array}{l}\text { http://duaputrapetir.indonetwork.co.id/47 } \\
\text { 26556/pipa-seamless-pipa-stainless-steel- } \\
\text { pipa-hitam-pipa-galvanis.htm }\end{array}$ \\
\hline $\begin{array}{l}\text { Pipa medium } \\
\text { hitam 3/4 inchi }\end{array}$ & & $\begin{array}{l}\text { http://duaputrapetir.indonetwork.co.id/47 } \\
\text { 26556/pipa-seamless-pipa-stainless-steel- } \\
\text { pipa-hitam-pipa-galvanis.htm }\end{array}$ \\
\hline $\begin{array}{l}\text { Pipa medium } \\
\text { hitam 3 inchi }\end{array}$ & SCH-40 & $\begin{array}{l}\text { http://wanakencanagroup.com/?page_id= } \\
\text { 3396 }\end{array}$ \\
\hline Palt baja 0,5 mm & $\begin{array}{l}\text { JIS G 3141 } \\
\text { SPCC SD }\end{array}$ & $\begin{array}{l}\text { http://duaputrapetir.indonetwork.co.id/47 } \\
\text { 26556/pipa-seamless-pipa-stainless-steel- } \\
\text { pipa-hitam-pipa-galvanis.htm }\end{array}$ \\
\hline $\begin{array}{l}\text { Pipa sambungan } \\
\text { galvanis }\end{array}$ & $\begin{array}{l}\text { ASTM A53 } \\
\text { SCH-40 }\end{array}$ &
\end{tabular}

\section{- Prosedur Pembuatan}

Berikut adalah langkah-langkah dalam pembuatan dan perakitan alat pengolah limbah plastik:

\section{Pembuatan Ruang Bakar}

Bahan yang digunakan adalah drum bekas, dengan dimensi ukuran sebagai berikut:

- Diameter ruang bakar :59 cm

- Diameter lubang atas ruang bakar $\quad: 31 \mathrm{~cm}$

- Tinggi ruang bakar $\quad: 35 \mathrm{~cm}$

- Tinggi pintu masuk kompor/biomassa $: 15 \mathrm{~cm}$

- Lebar pintu masuk kompor/biomassa : $: 37 \mathrm{~cm}$

Setelah menentukan dimensi ukuran langkah selanjutnya adalah melakukan pemotongan dengan menggunakan mesin gerinda tangan.

\section{Pembuatan Tabung Reaktor}

Bahan yang digunakan adalah lembar plat $3 \mathrm{~mm}$ dan pipa sambungan galvanis dengan dimensi ukuran sebagai berikut:

- Tinggi reaktor

$$
\begin{aligned}
& : 45 \mathrm{~cm} \\
& : 30 \mathrm{~cm} \\
& : 12 \mathrm{~cm} \\
& : 6 \mathrm{~cm} \\
& : 12,7 \mathrm{~cm}
\end{aligned}
$$$$
\text { Diameter reaktor }
$$$$
\text { Diameter lubang atas reaktor }
$$

- Diameter pipa sambungan galvanis

Setelah dimensi ukuran telah ditentukan maka langkah selanjutnya adalah melubangi bagian atas reaktor dengan menggunakan pahat besi. Setelah bagian atas tabung reaktor selesai dilubangi maka pipa sambungan Galvanis diletakkan di bagian yang telah dilubangi tadi lalu di las.

\section{Pembuatan Pipa Penghubung Dan Pipa Penadah Uap}

Bahan yang digunakan adalah pipa medium hitam 3/4 inchi, pipa medium hitam 3 inchi, lembar plat besi $2 \mathrm{~mm}$ dan pipa sambungan galvanis dengan dimensi ukuran sebagai berikut:

- Panjang pipa medium hitam $3 / 4$ inchi : $11 \mathrm{~cm} 1$ buah dan $21 \mathrm{~cm} 1$ buah 


\section{Jurnal Mekanova \\ Vol 5. No. 2, Oktober 2019 \\ ISSN : 2502-0498}

- Panjang pipa medium hitam 3 inchi

- Tinggi pipa galvanis

- Diameter lembar plat besi $2 \mathrm{~mm}$
: $20 \mathrm{~cm} 2$ buah

: $8 \mathrm{~cm}$

: 7,62 cm (4 buah) dan ukuran

$12.7 \mathrm{~cm}$ (1 Buah) pada bagian tengah dilubangi dengan

diameter $2 \mathrm{~cm}$.

Setelah dimensi ukuran ditentukan maka langkah selanjutnya adalah menghubungkan pipa medium hitam $3 / 4$ inchi yang berukuran $11 \mathrm{~cm}$ dengan pipa Galvanis lalu di las. Langkah selanjutnya adalah menghubungkan bagian kondensor I dan II yang telah di las terlebih dahulu. Dan langkah akhir dari pembuatan komponen ini adalah melubangi bagian bawah kondensor, lubang ini sebagai tempat penyalur minyak yang dihasilkan nantinya.

\section{- Perakitan Alat}

Setelah komponen-komponen seperti ruang bakar, tabung reaktor dan pipa penadah uap selesai dibuat, maka langkah selanjutnya adalah merakit komponen-komponen tersebut sesuai dengan yang direncanakan. Adapun tahap-tahap perakitannya adalah sebagai berikut:

- Tabung reaktor dihubungkan terlebih dahulu dengan pipa penadah uap, dengan cara menyambungkan pipa sambungan berulir pada tabung reaktor dengan pipa sambungan berulir pada pipa penadah uap dan diputar searah jarum jam.

- Setelah perakitan bagian tabung reaktor dan pipa penadah uap selesai, barulah di hubungkan dengan ruang bakar dengan cara memasukan tabung reaktor kedalam ruang bakar melalui bagian atas ruang bakar yang telah dilubanngi.

\section{- Diagram Alir Perancangan}

Flowchart perancangan alat pengolah limbah plastik ditunjukkan pada gambar 3.2 berikut:

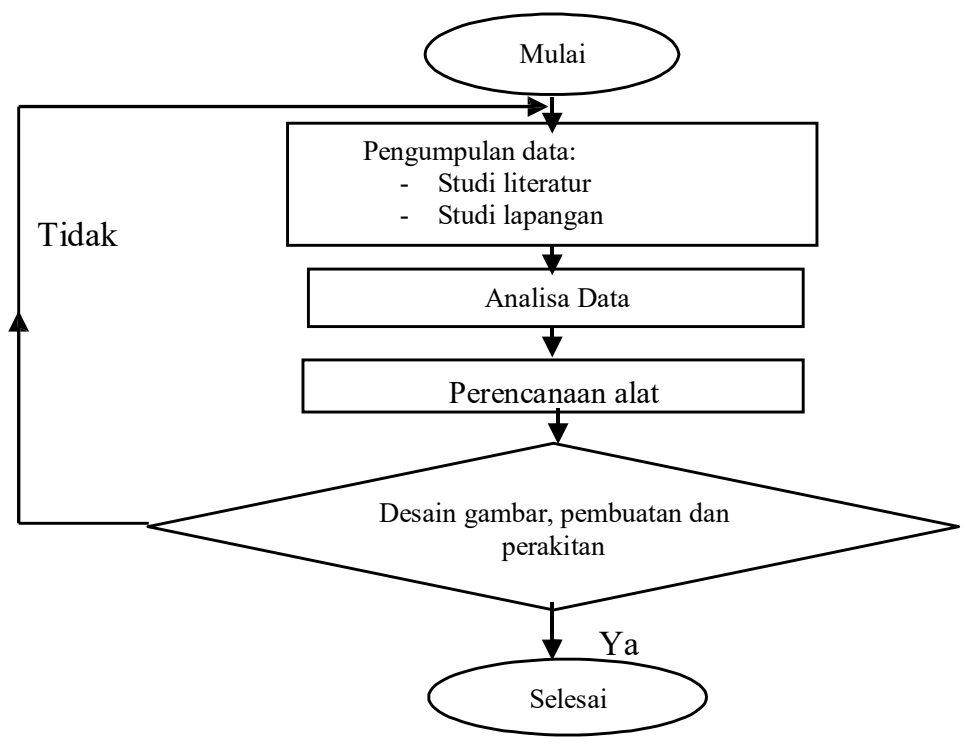

Gambar 2 Flowchart penelitian 
Jurnal Mekanova

Vol 2. No. 3, November 2016

ISSN : 2502-0498

\section{HASIL DAN PEMBAHASAN}

Hasil Desain Gambar Alat Pengolah Limbah Plastik

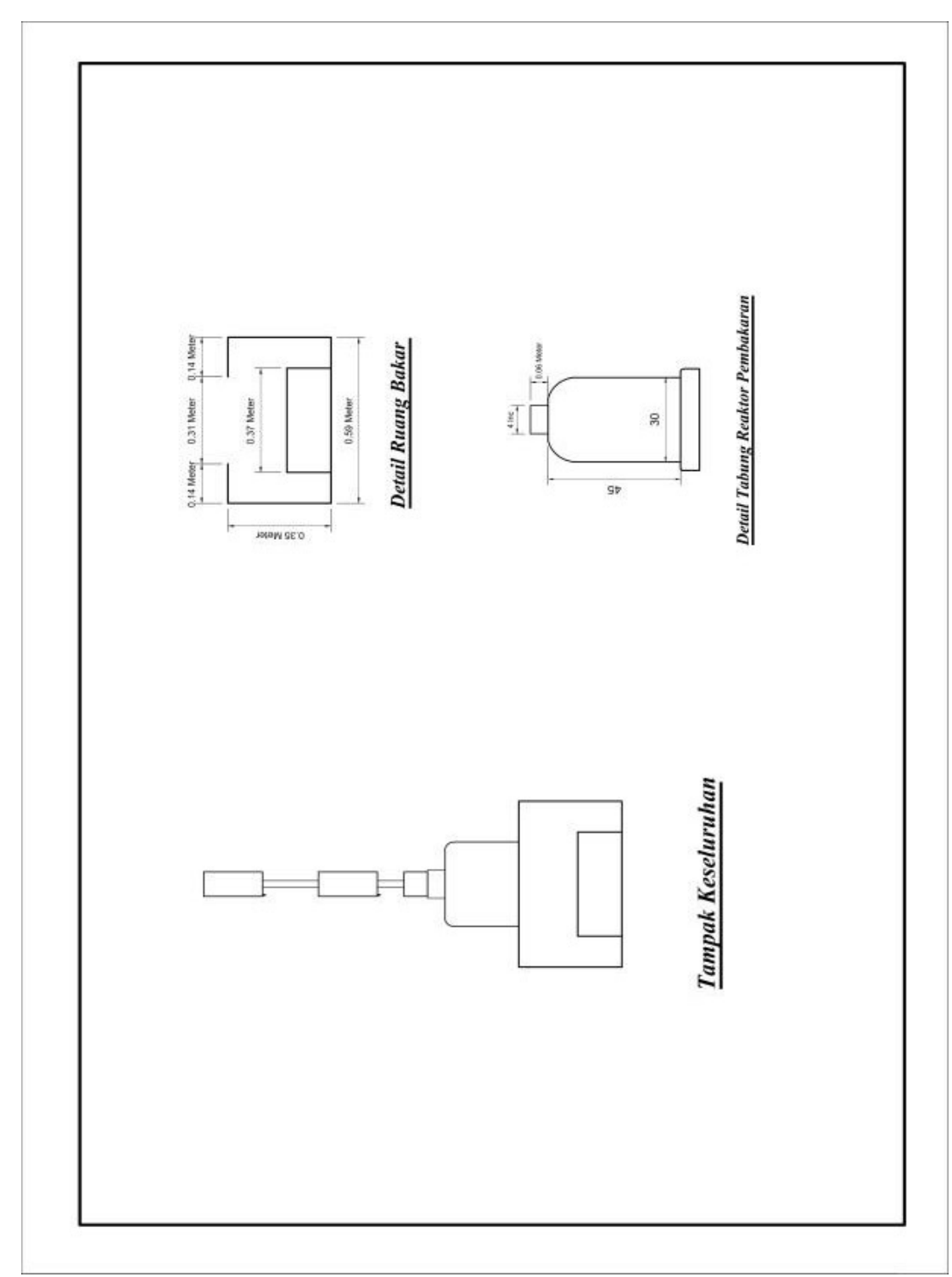


Vol 2. No. 3, November 2016

ISSN : 2502-0498

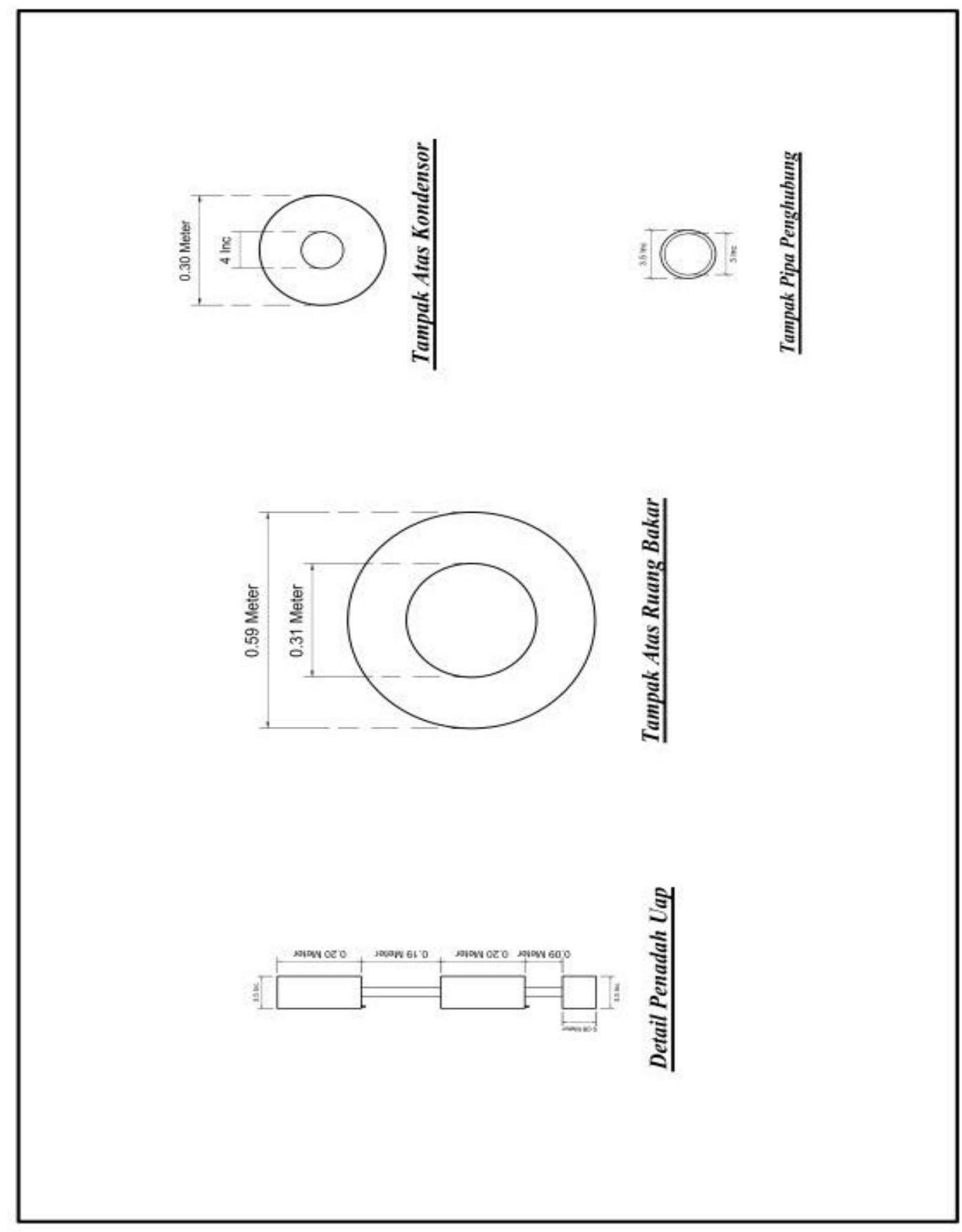




\section{Jurnal Mekanova}

Vol 2. No. 3, November 2016

ISSN : 2502-0498

\section{Hasil Pembuatan Dapur/Ruang Bakar}

Hasil pembuatan dapur/ruang bakar sesuai desain diperlihatkan dalam gambar $4.1 \mathrm{~b}$ berikut ini:

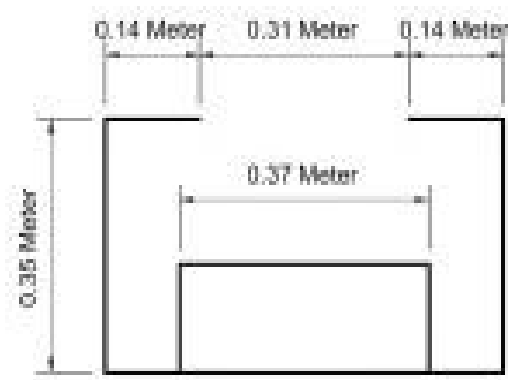

Gambar 3 a Desain ruang bakar Sumber: Penelitian

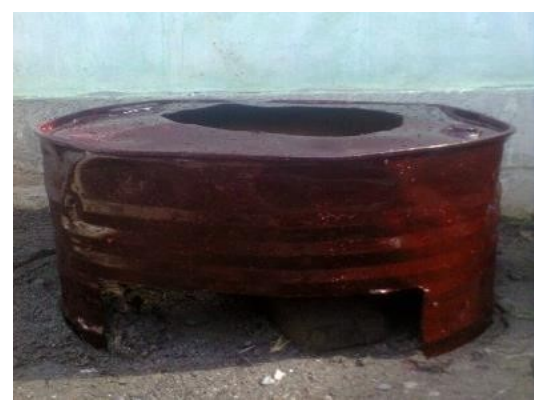

Gambar 3 b Hasil pembuatan ruang bakar Sumber: Penelitian

\section{Hasil Pembuatan Tabung Reaktor}

Hasil pembuatan tabung reaktor sesuai desain diperlihatkan dalam gambar $4 \mathrm{~b}$ berikut ini:

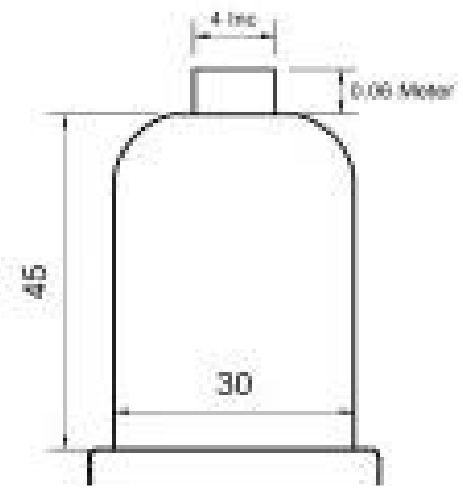

Gambar 4 a Desain Reaktor Sumber: Penelitian

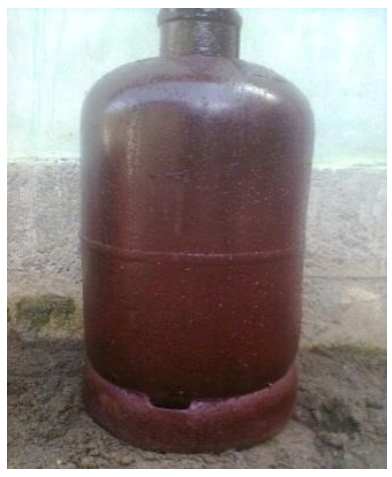

Gambar 4 b Hasil pembuatan tabung reaktor Sumber: Penelitian

\section{Hasil Pembuatan Pipa Penghubung Dan Pipa Penadah Uap}

Hasil pembuatan tabung reaktor sesuai desain diperlihatkan dalam gambar $5 \mathrm{~b}$ berikut ini

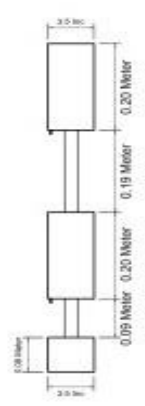

Gambar 5 a Desain pipa penghubung Dan pipa penadah uap

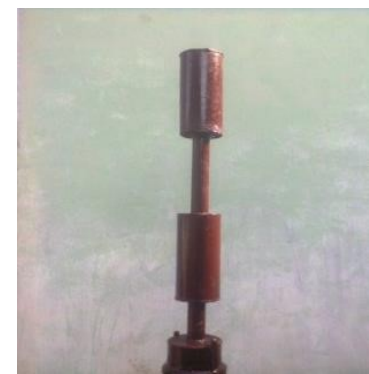

Gambar 5 b Hasil pembuatan pipa penghubung dan pipa penadah uap 


\section{Jurnal Mekanova \\ Vol 2. No. 3, November 2016 \\ ISSN : 2502-0498}

\section{- Hasil Perakitan}

Hasil perakitan alat pengolah limbah plastik sesuai desain diperlihatkan dalam gambar 6 sebagai berikut:

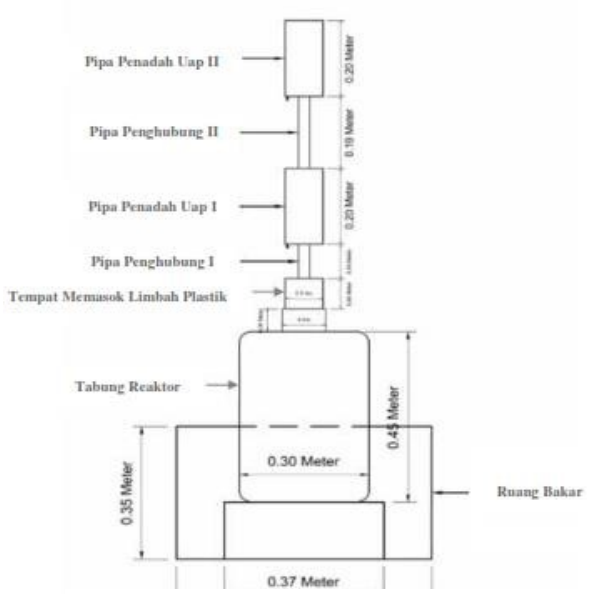

Gambar 6 a Desain Alat

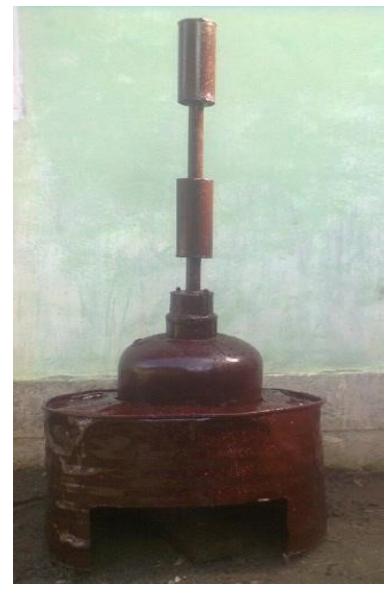

Gambar 6 b Hasil perakitan alat

\section{- Kapasistas Alat}

Untuk menentukan kapasistas alat pengolah limbah plastik dalam perencanaan ini dihitung berdasarkan luas volume tabung reaktor dari alat yang direncanakan. Dengan menggunakan rumus berikut, diperoleh hasil kapasitas alat sebagai berikut:

$$
v=\pi \cdot r^{2} \cdot t
$$

Maka:

$$
\begin{aligned}
\mathrm{v} & =\pi \mathrm{r}^{2} \cdot \mathrm{t} \\
& =3,14.14^{2} \cdot 45 \\
& =27694 \cdot 8 \mathrm{~cm}^{3}
\end{aligned}
$$

Dari luas volume tabung raktor yang didapat maka telah diperoleh kapasitas alat 3 sampai $4 \mathrm{~kg} /$ produksi.

\section{- Pembahasan}

Dari hasil pembuatan dan perakitan alat pengolah limbah plastik yang terpenting adalah dalam proses pengelasan. Dibutuhkan Ketelitian dalam pengerjaannya agar hasil yang optimal bisa didapatkan. Pengelasan yang kurang tepat dan tidak teliti akan mengakibatkan kebocoran, hal ini sangat berpengaruh pada hasil pengujian dan kualitas alat ini sendiri.

\section{KESIMPULAN}

Berdasarkan hasil perencanaan alat pengolah limbah plastik maka dapat disimpulkan sebagai berikut:

1. Telah selesai dirancang sebuah alat pengolah limbah plastik dengan menggunakan bahan bakar biomassa dengan bahan baku yang mudah diperoleh disekitar Kota Meulaboh dan Nagan Raya.

2. Alat pengolah limbah plastik ini berkapasitas 3 sampai dengan $4 \mathrm{~kg} /$ produksi.

3. Alat pengolah limbah plastik telah dibuat dan dirakit sesuai dengan hasil perancangan yang direncanakan. Dalam proses pembuatan dan perakitan alat pengolah limbah plastik ini sangatlah dibutuhkan ketelitian dalam pengerjaannya, Agar hasil yang 
optimal bisa kita dapatkan. Ketelitian yang sangat dibutuhkan pembuatan alat ini adalah pada langkah pengelasan.

\section{SARAN}

Disarankan dalam pembuatan/perakitan alat pengolah limbah plastik alangkah baiknya menggunakan bahan-bahan yang sesuai dengan kebutuhan dari alat dan yang mudah didapatkan dipasaran dengan harga terjangkau dan juga dapat memanfaaatkan bahan daur ulang sebagai material untuk membuat alat.

\section{DAFTAR PUSTAKA}

1. Sularso, 1987, "Dasar Perencanaan dan Pemilihan Elemen Mesin", Pradnya Paramita, Jakarta.

2. Surdia Ms. Met. E., Prof, Ir. Tata Dan Saito, Prof. DR. Shinroku, Pengetahuan Bahan Teknik,PT. Pradnya Paramita Jalan Bunga 8-8A,Jakarta, 2000.

3. Kadir, 2012. "Kajian Pemanfaatan Sampah Plastik Sebagai Sumber Bahan Bakar Cair", Dinamika Jurnal Ilmiah Teknik Mesin, ISSN : 2085-8817, Vol. 3 No. 2

4. Budi Surono, Untoro, 2013. "Berbagai Metode Konversi Sampah Plastik Menjadi Bahan Bakar Minyak", Jurusan Teknik Mesin Universitas Janabadra Yogyakarta, ISSN 2088-3676.

5. Budiyantoro, C., 2010, Thermoplastik Dalam Industri, Teknika Media, Surakata.

6. Das, S. dan Pande, S., 2007, Pyrolysis And Catalytic Craking Of Municipal Plastic Waste For Recovery Of Gasoline Range Hydrocarbons, Thesis, Chemical Engineering Department National Institute Of Technology Rourkela.

7. Wahyudi, I., 2001. Pemanfaatan Blotong Menjadi Bahan Bakar Cair Dan Arang Dengan Proses Pirolisis. Jurusan Teknik Lingkungan FTSP UPN "Veteran" Jatim.

8. Ramadhan, Aprian., P Dan Ali, Munawar, Pengolahan Saampah Plastik Menjadi Minyak Menggunakan Proses Pirolisis, Progdi Teknik Lingkungan, Fakultas Teknik Sipil Dan Perencanaan, Universitas Pembangunan Nasional "Veteran" Jawa Timur

9. Daryanto, Drs., 2007, Dasar-Dasar Teknik Mesin, PT Rineka Cipta, Jakarta.

10. Mikell P. Groover, 2010, Fundamentals of Modern Manufacturing, John Wiley \& Sons, United States

11. W Kenyon, Dines Ginting. 1985. Dasar-Dasar Pengelasan. Erlangga. Jakarta.

12. Caglar, A., \& Aydinli, B., 2009, "Isothermal co-Pyrolysis of Hazelnut Shell and Ultra-High Molecular Weight Polyethylene: the Effect of Temperature and 


\section{Jurnal Mekanova}

Vol 2. No. 3, November 2016

ISSN : 2502-0498

Composition on the Amount of Pyrolysis Products", Journal of Analytical and Applied Pyrolysis. 86 , 304-309.

13. Fajri Nugraha, Mahendra., Wahyudi, Arifuddin dan Gunardi, Ignatius., Pembuatan Fuel Dari Liquid Pirolisis Plastik Polipropilen Melalui Proses Reforming Dengan Katalis $\mathbf{N i O} / \mathbf{T}-\mathbf{A l}_{2} \mathbf{O}_{3}$, Jurusan Teknik Kimia, Fakultas Teknologi Industri, Institut Teknologi Sepuluh Nopember (ITS), Jl. Arief Rahman Hakim, Surabaya 60111 Indonesia, Jurnal Teknik Pomits Vol.2, No. 2, (2013) ISSN: 23373539 (2301-9721 Print)

14. Http://pelastikjadiminyak.blogspot.com/2013/07/ecogreen-alat-pengolah-sampahpelastik.html.

15 Http://bsn.go.id/main/berita/berita_det/2160\#.VNWT-11b-o8.

16. Http://wanakencanagroup.com/?page_id=3396

17. Http://duaputrapetir.indonetwork.co.id/4726556/pipa-seamless-pipa-stainless-steelpipa-hitam-pipa-galvanis.htm

18. Http://sekolah007.blogspot.ca/2013/04/metalografi-adalah-suatu-teknik-atau.html

19. Http://id.wikipedia.org/wiki/Pengukuran

$20 \mathrm{Https} / /$ yefrichan.wordpress.com/category/bahan-kuliah/page/18/

$21 \mathrm{Http}: / /$ misranindustri.blogspot.co.id/2014/02/pengelasan.html 